\title{
The effects of Saccharomyces cerevisiae supplementation on intake, nutrient digestibility, and rumen fluid pH in Awassi female lambs
}

Belal S. Obeidat ${ }^{1}$, Kamel Z. Mahmoud ${ }^{1}$, Mohammad D. Obeidat ${ }^{1}$, Mysaa Ata ${ }^{2}$, Rami T. Kridli ${ }^{1}$, Serhan G. Haddad ${ }^{1}$, Hosam H. Titi ${ }^{3}$, Khaleel I. Jawasreh ${ }^{1}$, Hosam J. Altamimi ${ }^{1}$, Hadil S. Subih ${ }^{4}$, Safaa M. Hatamleh ${ }^{1}$, Majdi A. Abu Ishmais and Ruba Abu Affan ${ }^{1}$

1. Department of Animal Production, Faculty of Agriculture, Jordan University of Science and Technology, Irbid 22110, Jordan; 2. Department of Animal Production and Protection, Faculty of Agriculture, Jerash University, Jerash 26150, Jordan; 3. Department of Animal Production, Faculty of Agriculture, University of Jordan, Amman 11942, Jordan;

4. Department of Nutrition and Food Technology, Faculty of Agriculture, Jordan University of Science and Technology, Irbid 22110, Jordan.

Corresponding author: Belal S. Obeidat, e-mail: bobeidat@just.edu.jo

Co-authors: KZM: kmahmoud@just.edu.jo, MDO: mdobeidat@just.edu.jo, MA: m.atta@jpu.edu.jo,

RTK: rkridli@just.edu.jo, SGH: shaddad@just.edu.jo,HHT: htiti@ju.edu.jo, KIJ: kijawasreh@just.edu.jo,

HJA: hjaltamimi@just.edu.jo, HSS: hssubih@just.edu.jo, SMH: seef.islam.sh@gmail.com, MAAI: majdi@just.edu.jo, RAA: roba_tobasy@yahoo.com

Received: 19-03-2018, Accepted: 12-06-2018, Published online: 30-07-2018

doi: 10.14202/vetworld.2018.1015-1020 How to cite this article: Obeidat BS, Mahmoud KZ, Obeidat MD, Ata M, Kridli RT, Haddad SG, Titi HH, Jawasreh KI, Altamimi HJ, Subih HS, Hatamleh SM, Ishmais MAA, Affan RA (2018) The effects of Saccharomyces cerevisiae supplementation on intake, nutrient digestibility, and rumen fluid $\mathrm{pH}$ in Awassi female lambs, Veterinary World, 11(7): 1015-1020.

\begin{abstract}
Aim: The aim of this study was to evaluate the effect of feeding low (LO)- or high (HI)-fiber diets supplemented with Saccharomyces cerevisiae (SC) on nutrient intake, digestibility, nitrogen balance, rumen fluid $\mathrm{pH}$, and serum concentrations of glucose and urea nitrogen in Awassi female lambs in a $2 \times 2$ factorial arrangement of treatments.

Materials and Methods: Experimental diets were as follows: (1) LO-fiber diet with no SC supplementation (-LO), (2) LO-fiber diet supplemented with SC (+LO), (3) HI-fiber diet with no SC supplementation (-HI), or (4) HI-fiber diet supplemented with SC $(+\mathrm{HI})$. Eight female lambs were used in a replicated $4 \times 4$ Latin square design with 15 -day experimental periods (10-day adaptation period and 5-day collection period).

Results: A fiber $\times \mathrm{SC}$ interaction $(\mathrm{p} \leq 0.05)$ was detected for dry matter $(\mathrm{DM})$ and crude protein $(\mathrm{CP})$ intake among diets showing greater $\mathrm{DM}$ and $\mathrm{CP}$ intake for $+\mathrm{LO}$ diet compared to $+\mathrm{HI}$ group supplemented with $\mathrm{SC}$, whereas $-\mathrm{LO}$ and $-\mathrm{HI}$ were intermediate. A fiber $\times \mathrm{SC}$ interaction $(\mathrm{p}=0.05)$ was also detected for the neutral detergent fiber $(\mathrm{NDF})$ intake among diets. Intake of NDF was greater for the $-\mathrm{HI}$ diet compared with $+\mathrm{LO}$ and $-\mathrm{LO}$ diets. Similarly, NDF intake was greater for $+\mathrm{HI}$ diet than $-\mathrm{LO}$ diet. A tendency $(\mathrm{p}=0.07)$ for a fiber $\times \mathrm{SC}$ interaction was detected for acid detergent fiber $(\mathrm{ADF})$ intake among diets as well. ADF intake tended to be greater for HI-fiber diets. No difference was observed in the rumen fluid $\mathrm{pH}$ for lambs fed with the different diets. No fiber $\times$ SC interactions were detected for the digestibility of DM, CP, NDF, and ADF among dietary treatments. Digestibility of DM was greater $(72.9 \mathrm{~g} / 100 \mathrm{~g}$ vs. $67.1 \mathrm{~g} / 100 \mathrm{~g}$; $\mathrm{p}=0.0002)$ for LO versus HI fiber. However, NDF and ADF digestibilities were greater (60.8 and $61.9 \mathrm{~g} / 100 \mathrm{~g}$ vs. 55.8 and $52.7 \mathrm{~g} / 100 \mathrm{~g}$ for NDF and ADF digestibility, respectively; $\mathrm{p} \leq 0.01$ ) for the HI-fiber than the LO-fiber diets.
\end{abstract}

Conclusion: Results obtained in the current study indicate that SC supplementation has a minimal effect on the performance of Awassi female lambs fed with varying fiber levels.

Keywords: Awassi female lamb, intake, nutrients digestibility, yeast supplementation.

\section{Introduction}

Nutritional programs for ruminant animals focus on providing the precise level of nutrients at the proper time, to obtain optimal productivity and profitability [1]. Level and type of forages are among the most important factors that determine the effect of feed additives, such as yeast, on animal performance [2]. The most widely used additives in animal nutrition

Copyright: Obeidat, et al. Open Access. This article is distributed under the terms of the Creative Commons Attribution 4.0 International License (http://creativecommons.org/licenses/ by/4.0/), which permits unrestricted use, distribution, and reproduction in any medium, provided you give appropriate credit to the original author(s) and the source, provide a link to the Creative Commons license, and indicate if changes were made. The Creative Commons Public Domain Dedication waiver (http:// creativecommons.org/publicdomain/zero/1.0/) applies to the data made available in this article, unless otherwise stated. over the past decade are probiotics. Probiotics are live microorganisms that can provide a health benefit for the host animals and improve forage digestibility as well [3]. Saccharomyces cerevisiae (SC) has been found to improve ruminal fermentation [4], enhance microbial growth, and improve the stability of rumen fermentation. Moreover, supplementing yeast provides some nutrients during digestion which impact the rumen microbial population and function.

Many studies showed beneficial effects of yeast on the ruminal environment, the number of ruminal microbes, and microbial activity [5-7]. The number of ruminal microbes and cellulolytic bacteria increased with dietary yeast supplementation [8], due to the increase in the population of beneficial microorganisms. Adding yeast to dairy cattle diets was reported to 
enhance the overall performance through improving the efficiency of nutrient utilization [9].

Supplementing yeast with high (HI)- and low (LO)-fiber diets in sheep can test the hypothesis that the level of the fiber in the diet can impact the efficacy of yeast on performance. Therefore, this study aimed to evaluate the influence of SC supplementation on diets containing $\mathrm{LO}$ versus $\mathrm{HI}$ neutral detergent fiber (NDF) on nutrient intakes and digestibility, nitrogen balance, and rumen fluid $\mathrm{pH}$ in Awassi female lambs.

\section{Materials and Methods}

\section{Ethical approval}

The study was conducted at the Agricultural Research and Training Unit at Jordan University of Science and Technology (JUST). All procedures used in the study were approved by the JUST Institutional Animal Care and Use Committee (16/3/3/222).

\section{Experiment procedures}

Eight Awassi female lambs (6 months old) were used in $2 \times 2$ factorial arrangements to evaluate the effect of yeast (Levucell ${ }^{\mathbb{S}} \mathrm{SC}$, Lallemand, France; $3 \times 10^{9} / \mathrm{g}$ ) supplementation on the criteria listed above. Animals were housed in metabolic crates $(1.05 \mathrm{~m} \times 0.80 \mathrm{~m})$ and offered diets containing either LO or HI level of fiber (HI). Diets were as follows: (1) LO-fiber diet with no SC supplementation (-LO), (2) LO-fiber diet supplemented with SC (+LO), (3) HI-fiber diet with no SC supplementation (-HI), or (4) HI-fiber diet supplemented with SC $(+\mathrm{HI})$. To ensure complete consumption, SC $(0.25 \mathrm{~g} / \mathrm{head} /$ day $+10 \mathrm{~g}$ ground barley) was mixed with $50 \mathrm{~g}$ of the assigned diet throughout the experimental period. Diets were formulated to have similar crude protein $(\mathrm{CP})$ contents (analyzed; $140 \mathrm{~g} / \mathrm{kg} \mathrm{CP}$; dry matter [DM] basis). Diets were offered ad libitum (at 8:00 h) with free access to water throughout the study. The study was designed with four experimental periods; each period lasted for 15 days ( 10 days were used as adaptation to the metabolic crates and the experimental diets followed by 5 days for data collection). Offered and refused feeds were recorded from days 10 to 15 of each experimental period to evaluate intake.

Total fecal output was collected, weighed, and recorded, and then, a sample of $10 \mathrm{~g} / 100 \mathrm{~g}$ of each was kept for subsequent chemical analysis during the period from days 10 to 15 . During the collection period, urine was collected daily in buckets (containing $50 \mathrm{ml} 1 \mathrm{~N} \mathrm{HCl}$ ), weighed, and recorded, and $5 \mathrm{~g} / 100 \mathrm{~g}$ of each was kept for nitrogen analysis. On day 15 of each experimental period, $5 \mathrm{ml}$ of rumen fluid was collected from the ventral sac using a syringe fitted with a G14 needle at 0,2 , and $4 \mathrm{~h}$ after feeding (at 12: $00 \mathrm{~h}$ ) to evaluate rumen fluid $\mathrm{pH}$.

Following the Association of Official Analytical Chemists (AOAC) [10] procedures, diets and fecal samples were analyzed for DM, CP, NDF, and acid detergent fiber (ADF). Ingredient and chemical composition of the LO- and HI-fiber diets are presented in Table-1. At the end of each period, $10 \mathrm{ml}$ of blood samples were collected from the jugular vein to evaluate blood metabolites (glucose and urea nitrogen).

\section{Laboratory procedures}

At the end of the experiment, feed and fecal samples were dried at $55^{\circ} \mathrm{C}$ in a forced air oven to constant weight and ground to pass a $1 \mathrm{~mm}$ sieve (Brabender, Duisburg, Germany). These samples were analyzed for $\mathrm{DM}\left(100^{\circ} \mathrm{C}\right.$ in an air-forced oven for $24 \mathrm{~h}$ ), and nitrogen (Kjeldahl procedure; ${ }^{\# 976.06)}$ using AOAC procedures [10]. NDF and ADF analyses were performed using the Ankom ${ }^{2000}$ fiber analyzer apparatus (Ankom Technology Corporation, Macedon, NY, USA). The NDF analysis used sodium sulfite in the neutral detergent solution and a heat stable alpha-amylase. Both NDF and ADF are expressed with residual ash.

Blood samples were centrifuged (at $3000 \mathrm{rpm}$, for $15 \mathrm{~min}$ ) after $1 \mathrm{~h}$ of collection. Serum was immediately harvested and stored at $-20^{\circ} \mathrm{C}$ until the day of analysis. Serum concentrations of glucose and urea nitrogen were analyzed using commercial kits (BioSystems, S. A. Costa Brava, Barcelona, Spain) and according to the manufacturer's specifications. Absorbance was measured using a spectrophotometer (JENWAY 6105 ultraviolet/visible, Model 6105, Jenway Ltd., Felsted, Dunmow ESSEX CM6 3LB, UK).

\section{Statistical analysis}

This experiment was designed to test the effect of fiber levels during the presence or absence of yeast $(2 \times 2$ factorial treatments) by running two $4 \times 4$ Latin

Table-1: Ingredients and chemical composition of the LO- and HI-fiber diets fed to Awassi female lambs.

\begin{tabular}{lcc}
\hline Ingredient, \% DM & LO & HI \\
\hline Barley grain & 53 & 26 \\
Soybean meal (440 g/kg CP; solvent) & 11 & 17 \\
Alfalfa hay & 14 & 12 \\
Wheat straw & 20 & 43 \\
Salt & 1 & 1 \\
Limestone & 1 & 1 \\
Vitamin/mineral premix & + & + \\
\hline
\end{tabular}

Analyzed chemical composition, (\%)

\begin{tabular}{lcc}
\hline DM & 91.6 & 92.7 \\
CP & 14.1 & 13.8 \\
NDF & 37.6 & 52.0 \\
ADF & 17.8 & 29.1 \\
ME, Mcal/kg & 2.3 & 2.1 \\
\hline
\end{tabular}

${ }^{1}$ One $\mathrm{kg}$ was added for each $1000 \mathrm{~kg}$ mixed. Composition per kg contained (Vitamin A, 600,000 IU; Vitamin $D_{3}$, 200,000 IU; Vitamin E, 75 mg, Vitamin K3, 200 mg; Vitamin B1, $100 \mathrm{mg}$; Vitamin B5, $500 \mathrm{mg}$; lysine $0.5 \%$; DL-methionine, $0.15 \%$; manganese oxide, $4000 \mathrm{mg}$; ferrous sulfate, $15,000 \mathrm{mg}$; zinc oxide, 7000; magnesium oxide, $4000 \mathrm{mg}$; potassium iodide, $80 \mathrm{mg}$; sodium selenite, $150 \mathrm{mg}$; copper sulfate, $100 \mathrm{mg}$; cobalt phosphate, $50 \mathrm{mg}$, dicalcium phosphate, $10,000 \mathrm{mg}$. $\mathrm{DM}=$ Dry matter, $\mathrm{CP}=$ Crude protein, $\mathrm{NDF}=$ Neutral detergent fiber, $\mathrm{ADF}=$ Acid detergent fiber, $\mathrm{ME}=$ Metabolizable energy, $\mathrm{LO}=\mathrm{Low}, \mathrm{HI}=$ High 
Table-2: Effect of SC supplementation in Awassi female lambs fed with LO- and HI-fiber diets on nutrient intakes ( $\mathrm{g} / \mathrm{kg}$ $\mathrm{DM})$ and rumen fluid $\mathrm{pH}$.

\begin{tabular}{|c|c|c|c|c|c|c|c|c|}
\hline \multirow[t]{3}{*}{ Item } & \multicolumn{4}{|c|}{ Fiber $^{1}$} & \multirow[t]{3}{*}{ SEM } & \multicolumn{3}{|c|}{ p-value } \\
\hline & \multicolumn{2}{|c|}{ LO } & \multicolumn{2}{|c|}{ HI } & & \multirow[b]{2}{*}{ Fiber } & \multirow[b]{2}{*}{ SC } & \multirow[b]{2}{*}{ Fiber XSC } \\
\hline & +LO & -LO & $+\mathrm{HI}$ & $-H I$ & & & & \\
\hline \multicolumn{9}{|l|}{ Intake, g/kg } \\
\hline DM & $1390^{b}$ & $1265^{\mathrm{ab}}$ & $1143^{a}$ & $1281^{\mathrm{ab}}$ & 78.9 & 0.08 & 0.91 & 0.048 \\
\hline $\mathrm{CP}$ & $196^{b}$ & $178^{a b}$ & $158^{a}$ & $177^{\mathrm{ab}}$ & 11.0 & 0.03 & 0.93 & 0.05 \\
\hline NDF & $522^{\mathrm{bc}}$ & $475^{c}$ & $595^{\mathrm{ab}}$ & $666^{a}$ & 36.6 & 0.001 & 0.67 & 0.05 \\
\hline ADF & $247^{a}$ & $225^{a}$ & $332^{b}$ & $372^{b}$ & 19.7 & $<0.01$ & 0.58 & 0.07 \\
\hline Rumen fluid pH & 6.1 & 6.0 & 6.4 & 6.4 & 0.14 & 0.25 & 0.58 & 0.21 \\
\hline
\end{tabular}

${ }^{1}$ Diets were as follows: (1) LO-fiber diet with no SC supplementation (-LO), (2) LO-fiber diet supplemented with SC (+LO), (3) HI-fiber diet with no SC supplementation (-HI), or (4) HI-fiber diet supplemented with SC (+HI). $\mathrm{DM}=$ Dry matter, $\mathrm{CP}=$ Crude protein, $\mathrm{NDF}=$ Neutral detergent fiber, $A D F=$ Acid detergent fiber, $L O=L o w, H I=H i g h$, $\mathrm{SC}=$ Saccharomyces cerevisiae, $\mathrm{SEM}=$ Standard error of the mean

Table-3: Effect of SC supplementation in Awassi female lambs fed with LO- and HI-fiber diets on nutrient digestibility (\%).

\begin{tabular}{|c|c|c|c|c|c|c|}
\hline \multirow[t]{3}{*}{ Item } & \multicolumn{2}{|c|}{ Fiber $^{1}$} & \multirow[t]{3}{*}{ SEM } & \multicolumn{3}{|c|}{ p-value } \\
\hline & \multirow{2}{*}{$\frac{L O}{+L O-L O}$} & \multirow{2}{*}{$\frac{H I}{+H I-H I}$} & & \multirow[b]{2}{*}{ Fiber } & \multirow[b]{2}{*}{ SC } & \multirow[b]{2}{*}{ Fiber $\times$ SC } \\
\hline & & & & & & \\
\hline DM & 72.773 .1 & 66.068 .2 & 1.22 & $<0.001$ & 0.27 & 0.41 \\
\hline $\mathrm{CP}$ & 72.871 .9 & 70.274 .5 & 1.90 & 0.99 & 0 & 0 \\
\hline VDF & 55.156 .4 & 59.861 .9 & 1.93 & 0.011 & 0.3 & 0.84 \\
\hline ADF & $51.0 \quad 54.4$ & 60.963 .0 & 2.03 & $<0.001$ & 0.13 & 0.70 \\
\hline \multicolumn{7}{|c|}{ 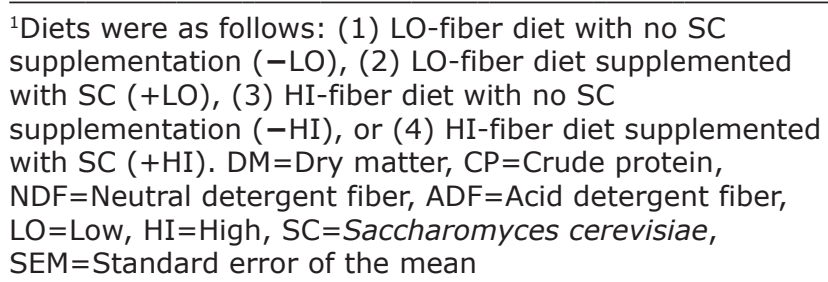 } \\
\hline
\end{tabular}

squares. Four animals were used in each square and sampled over four experimental periods (15 days for each period). Data analyses were conducted on measurements collected from pooled samples during day $11-15$ of the experimental periods. Experimental unit measurements were analyzed using the mixed model procedure of SAS (PROC MIXED; SAS Inc., Cary, NC, 2000) to account for the effects of square, animal within square, period, and treatment $(2 \times 2$ factorial; fiber levels vs. presence or absence of SC). Treatments were considered fixed effect; square, animal within square, and period were considered as random effects. Data are presented as least square means \pm standard error of the mean. Statistical significance was considered at $\mathrm{p} \leq 0.05$.

\section{Results}

The effect of SC supplementation on nutrient intakes and rumen fluid $\mathrm{pH}$ is presented in Table-2. The results clearly show that sheep fed with LO-fiber diets consumed more $(\mathrm{p} \leq 0.05) \mathrm{DM}$ and $\mathrm{CP}$; however, this increase was dependent on the presence or absence of SC. Adding SC to LO-fiber rations increased $\mathrm{DM}$ and $\mathrm{CP}$ intakes compared to their HI-fiber diet counterparts due to fiber $\times S C$ interaction $(p \leq 0.05)$.
A fiber $\times$ SC interaction $(p=0.05)$ was also detected for NDF intake among diets. Intake of NDF was greater for the $-\mathrm{HI}$ diet compared with $+\mathrm{LO}$ and $-\mathrm{LO}$ diets. Similarly, NDF intake was greater for the $+\mathrm{HI}$ than the $-\mathrm{LO}$ diet. There was a tendency $(p \leq 0.07)$ for the fiber $\times$ SC interaction to affect ADF intake. ADF intake was greater in lambs fed with HI-fiber diets. No difference was observed for the rumen fluid $\mathrm{pH}$ for lambs fed with the different diets.

The digestibility of DM, CP, NDF, and ADF is presented in Table-3. Female lambs consumed different diets had a similar $\mathrm{CP}$ digestibility; however, fiber content significantly altered DM, NDF, and ADF digestibilities. DM digestibility increased $(p<0.01)$ when sheep consumed LO-fiber diets compared to their counterparts on HI-fiber diets. To the contrary, HI-fiber diet was associated with higher $(p<0.05)$ digestibility of NDF and ADF. SC supplementation did not change the digestibility of the discussed variables.

The effects of SC supplementation in LO- or $\mathrm{HI}$-fiber diets on nitrogen balance are shown in Table-4. Female lambs fed with LO-fiber diets maintained higher $(p<0.05)$ nitrogen intake and excreted more $(\mathrm{p}<0.05)$ as well; however, these groups showed higher $(\mathrm{p}<0.05)$ nitrogen retention which was associated with lower $(\mathrm{p}<0.05)$ nitrogen losses through urine. There was a clear fiber $\times$ SC interaction $(p<0.05)$ for the nitrogen intake and an interaction tendency for the nitrogen retention variable. The SC supplementation increased nitrogen intake in groups fed with the LO-fiber diet and relatively increased its body retention. No fiber $\times \mathrm{SC}$ interaction was detected for nitrogen excreted in feces or urine.

No fiber $\times \mathrm{SC}$ supplementation interaction was detected for serum concentrations of glucose and urea nitrogen among diets (Table-5). Similarly, serum concentrations of glucose and urea nitrogen were not affected by the level of fiber or SC supplementation.

\section{Discussion}

The use of yeast as an additive for growing lambs is to optimize the use of dietary fiber, resulting in 
Table-4: Effect of SC supplementation in Awassi female lambs fed with LO- and HI-fiber diets on nitrogen balance ( $\mathrm{g} / \mathrm{d}$ ).

\begin{tabular}{|c|c|c|c|c|c|c|c|c|}
\hline \multirow[t]{3}{*}{ Item } & \multicolumn{4}{|c|}{ Fiber $^{1}$} & \multirow[t]{3}{*}{ SEM } & \multicolumn{3}{|c|}{ p-value } \\
\hline & \multicolumn{2}{|c|}{ LO } & \multicolumn{2}{|c|}{ HI } & & \multirow[b]{2}{*}{ Fiber } & \multirow[b]{2}{*}{ SC } & \multirow[b]{2}{*}{ Fiber $\times$ SC } \\
\hline & +LO & -LO & $+\mathrm{HI}$ & $-H I$ & & & & \\
\hline $\mathrm{N}$ intake & $31.4^{a}$ & $28.5^{\mathrm{ab}}$ & $25.3^{b}$ & $28.3^{\mathrm{ab}}$ & 1.76 & 0.03 & 0.94 & 0.046 \\
\hline $\mathrm{N}$ in feces & 8.5 & 8.1 & 7.3 & 7.3 & 0.52 & 0.01 & 0.61 & 0.47 \\
\hline $\mathrm{N}$ in urine & 6.6 & 6.4 & 7.8 & 8.1 & 0.38 & 0.002 & 0.89 & 0.53 \\
\hline $\mathrm{N}$ retained & $16.3^{a}$ & $14.1^{a}$ & $10.2^{\mathrm{b}}$ & $12.9^{a b}$ & 1.39 & 0.01 & 0.87 & 0.07 \\
\hline
\end{tabular}

${ }^{1}$ Diets were as follows: (1) LO-fiber diet with no SC supplementation (-LO), (2) LO-fiber diet supplemented with $\mathrm{SC}(+\mathrm{LO})$, (3) HI-fiber diet with no SC supplementation (--HI), or (4) HI-fiber diet supplemented with SC (+HI), $\mathrm{LO}=\mathrm{Low}, \mathrm{HI}=\mathrm{High}, \mathrm{SC}=$ Saccharomyces cerevisiae, SEM=Standard error of the mean

Table-5: Effect of SC supplementation in Awassi female lambs fed with LO- and HI-fiber diets on serum concentrations $(\mathrm{mg} / \mathrm{dL})$ of glucose and urea $\mathrm{N}$.

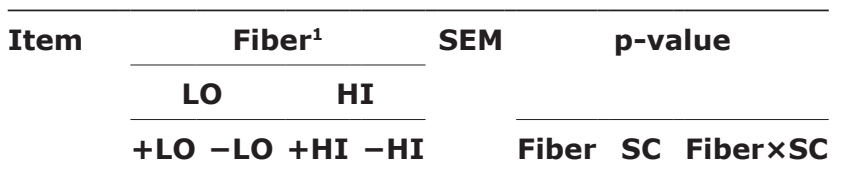

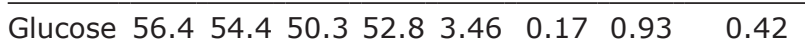

$\begin{array}{lllllllll}\text { Urea N } & 19.6 & 18.1 & 19.0 & 18.3 & 1.23 & 0.89 & 0.37 & 0.75\end{array}$

${ }^{1}$ Diets were as follows: (1) LO-fiber diet with no SC supplementation (-LO), (2) LO-fiber diet supplemented with SC (+LO), (3) HI-fiber diet with no SC

supplementation $(-\mathrm{HI})$, or (4) HI-fiber diet supplemented with $\mathrm{SC}(+\mathrm{HI}), \mathrm{LO}=\mathrm{Low}, \mathrm{HI}=$ High, $\mathrm{SC}=$ Saccharomyces cerevisiae, $\mathrm{SEM}=$ Standard error of the mean

improved growth. Moreover, yeast may affect ruminal $\mathrm{pH}$ by reducing the activity of lactic acid producing bacteria and thus increasing its nutrient availability [11]. In the current study, DM and CP intakes were greater for animals fed with LO-fiber diets supplemented with SC $(+\mathrm{LO})$. This indicated that the level of fiber has a detrimental effect on DM intake, consistent with results of previous studies [12,13]. Hassan and Mohammed [14] found that DM intake was not affected by yeast addition to different roughage to concentrate ratios while $\mathrm{CP}$ intake increased when diets contained less fiber. Consistent with these results, intake did not change by adding SC to diets with different roughage to concentrate [15] and when added to concentrate diets [16] in male lambs. On the contrary, Hansen et al. [17] reported an increase in DM intake when adding yeast culture to diets fed to buffaloes.

Moreover, an interaction between SC supplementation and daily feed intake of ADF and NDF was previously reported [15]. CP intake increased with $\mathrm{HI}$ concentrates supplemented with SC, whereas ADF and NDF increased with HI roughage supplemented with SC. Those findings might be due to the stabilization of ruminal fermentation and activity due to SC supplementation, which might have enhanced the intake of CP [18]. Ghasemi et al. [19] observed that SC supplementation was linked with increased NDF intake. The increase in ADF intake could be due to SC addition and fiber content, which can be attributed to the improvement of the digestibility of this nutrient (Table-3). In general, any increase in the rate of digestion should enhance the rate of passage that increases animal intake of nutrients [20].

Contrary to our finding, Hasunuma et al. [21] found that DM intake was not affected by yeast supplementation to dairy cattle. Furthermore, Whitley et al. [22] reported that DM intake was not impacted by yeast supplementation due to the limited involvement of yeast with ruminal microbes, which is required for improving ruminal fermentation and increasing intake.

Results reported in the present study revealed no fiber $\times \mathrm{SC}$ interactions with respect to digestibility of DM, CP, NDF, and ADF. Digestibility of nutrients is enhanced by the type of fiber used. Bueno et al. [23] reported similar results to ours. They found that the interaction between adding yeast and diets with different levels of fiber to concentrate ratios was not statistically significant, which indicates that active yeast supplementation was effective on the two diets independent of their fiber to concentrate ratio. Active yeast can improve the ruminal environment, mainly by keeping $\mathrm{pH}$ values around neutrality and avoiding drastic $\mathrm{pH}$ drop in diets with LO-fiber proportions [24]. Other researchers suggested that yeast culture inclusion has an important role in nutrient digestion for animals maintained on HI-forage diets [25]. Intake and digestion of feeds are dependent on the initial rate of fiber digestion; early stimulus of ruminal action would positively enhance feed consumption and might improve animal performance [26].

Digestibility of CP was not affected in lambs fed with diets supplemented with SC or by the type of fiber used, while NDF and ADF digestibilities improved in lambs fed with HI-fiber diets. Wiedmeier et al. [27] found higher CP digestibility values in cattle fed with yeast-supplemented rations. This supplementation might stimulate proteolytic bacteria that significantly increase CP digestibility. In addition, Wohlt et al. [28] reported that yeast supplementation improves $\mathrm{CP}$ digestibility and, as a result, DM intake in cows. Other researchers reported that some yeast cultures impacted the number of cellulolytic bacteria in the rumen and thus increased cellulose degradation. They also suggested that SC supplementation stimulates the rate, rather than the extent, of fiber digestion in the rumen by its microorganisms [4]. 
A fiber $\times$ SC supplementation interaction was detected for the nitrogen intake among diets, showing that nitrogen intake was improved with the different fiber levels. These results contradict those of Bueno et al. [23] who found that nitrogen balance was not modified by active yeast supplementation regardless of the levels of fed fiber. Fecal nitrogen excretion was improved, and urinary nitrogen excretion was reduced for female lambs fed with the LO diet compared to female lambs fed with the HI diet. Gad et al. [29] reported that nitrogen balance improves with lower than HI dietary fiber and attributed this finding to the improvement of $\mathrm{CP}$ digestibility. Furthermore, Cole et al. [30] reported that lambs raised on rations supplemented with yeast had greater nitrogen -balance than controls. One probable explanation for the increase in the nitrogen balance could be related to the improvement in the production of microbes and, as a result, increased production of microbial protein. In addition, the improvement in nitrogen balance could be related to the increase in the utilization of ammonia [31] and/ or due to the availability of fermentable carbohydrates in the rumen.

The addition of SC to female lamb diets containing different fiber levels did not affect serum concentrations of glucose and urea nitrogen. Our results are in agreement with the results obtained by Khormizi et al. [32] who indicated that plasma content of glucose and urea nitrogen was not affected by supplementation with yeast. Raghab et al. [33], on the other hand, recorded that dietary supplementation of yeast resulted in a significant increase in serum glucose concentration in calves. The lack of effect of SC supplementation on these parameters in this experiment might be due to the inability of yeast to influence protein and fibers degradation.

\section{Conclusion}

Supplementing SC has a minimal effect on the performance (intake, digestibility, and nitrogen retention as well as blood metabolites) of Awassi female lambs fed with two levels of fiber. The relationships between SC supplementation and fiber levels are worth further investigation to determine the situations where supplemental SC is expected to improve animal performance.

\section{Authors' Contributions}

BSO: Designing, supervising, and writing the manuscript, KZM: Helping in statistical analysis and writing the manuscript, MDO: Drafting the manuscript, MA: Drafting the manuscript, RTK: Helping in technical writing, SGH: Drafting the manuscript, HHT: Drafting the manuscript, KIJ: Drafting the manuscript, HJA: Drafting The manuscript, HSS: Drafting the manuscript, SMH: Field work, MAAI: Doing the laboratory analyses. RAA: Field work. All authors read and approved the final manuscript.

\section{Acknowledgments}

The authors wish to thank the Deanship of Scientific Research, Jordan University of Science and Technology for the financial support of this project (Grant \#: 67/2015).

\section{Competing Interests}

The authors declare that they have no competing interests.

\section{References}

1. Gaafar, H.M.A., Abdel-Raouf, E.M. and EL-Reidy, K.F.A. (2010) Effect of fibrolytic enzyme supplementation and fiber content of total mixed ration on productive performance of lactating Buffaloes. Slovak J. Anim. Sci., 43: 147-153.

2. Piva, G., Belladonna, S., Fusconi, G. and Sicbaldi, F. (1993) Effect of yeast on dairy cow performance, ruminal fermentation, blood component and milk manufacturing properties. J. Dairy Sci., 76: 2717-2722.

3. Sousa, D.O., Oliveira, C.A., Velasquez, A.V., Souza, J.M., Chevaux, E., Mari, L.J. and Silva, L.F.P (2018) Live yeast supplementation improves rumen fiber degradation in cattle grazing tropical pastures throughout the year. Anim. Feed Sci. Technolo., 236: 149-155.

4. Dehghan-Banadaky, M., Ebrahimi, M., Motameny, R. and Heidari, S.R. (2013) Effects of live yeast supplementation on mid-lactation dairy cows performances, milk composition, rumen digestion and plasma metabolites during hot season. J. Appl. Anim. Res., 41: 137-142.

5. Alshaikh, M.A., Alsiadi, M.Y., Zahran, S.M., Mogawer, H.H. and Aalshowime, T.A. (2002) Effect of feeding yeast culture from different sources on the performance of lactating Holstein cow in Saudi Arabia. Asian Aust. J. Anim. Sci., 15: 352-356.

6. Lila, Z.A., Mohammed, N., Yasui, T., Kurokawa, Y., Kanda, S. and Itabashi, H. (2004) Effects of twin strain of Saccharomyces cerevisiae live cells on mixed ruminal microorganism fermentation in vitro. J. Anim. Sci., 82: $1847-1854$.

7. Chevaux E. and Fabre, M.M. (2007) Probiotic yeast in small ruminants. Feed Mix, 15: 28029-28036.

8. Dawson K.A., Neuman, K.E. and Boling, J.A. (1990) Effects of microbial supplements containing yeast and lactobacilli on roughage-fed ruminal microbial activities. $J$. Anim. Sci., 68: 3392-3398.

9. Yuan, K., Liang, T., Muckey, M.B., Mendonca, L.G.D., Hulbert, L.E., Elrod, C.C. and Bradford, B.J. (2015) Yeast product supplementation modulated feeding behavior and metabolism in transition dairy cows. J. Dairy Sci., 98: $532-540$.

10. AOAC, (1990) Official Methods of Analysis. $15^{\text {th }}$ ed. Association of Official Analytical Chemists, Washington, DC.

11. Williams, P.V., Tait, C.G., Innes, G.M. and Newbold, C.J. (1991) Effects of the inclusion of yeast culture (Saccharomyces cerevisiae plus growth medium) in the diet of dairy cows on milk yield and forage degradation and fermentation patterns in the rumen of Steers. J. Anim. Sci., 69: 3016-3026.

12. Degirmencioglu, T., Sentürklü, S., Özbilgin, S. and Özcan, T. (2013) Effects of Saccharomyces cerevisiae addition to Anatolian water buffalo diets on dry matter intake, milk yield, milk composition and somatic cell count. Macedonian J. Anim. Sci., 3: 193-198.

13. Giger-Reverdin, S., Sauvant, D., Tessier, J., Bertin, G. and Morand-Fehr, P. (2004) Effect of live yeast culture supplementation on rumen fermentation in lactating dairy goats. $S$. Afr. J. Anim. Sci., 34: 59-61.

14. Hassan, S.A. and Mohammed, S.F. (2014) Effects of 
Saccharomyces cerevisiae supplementation on growth rate and nutrient digestibility in Awassi lambs fed diets with different roughage to concentrate ratios. Biochem. Biotech. Res., 2: 37-43.

15. Kumari, N.N., Reddy, Y.R., Blumme, M., Nagalakshmi, D., Sudhakar, K, Monika, T. and Pavani, M. (2012) Effect of roughage to concentrate ratio of sweet sorghum (Sorghum biclor L. Moench) bagasse-based complete diet on nutrient utilization and microbial N supply in lambs. J. Vet. Sci., 44: 17-24,

16. Obeidat, B.S. (2017) The effects of feeding olive cake and Saccharomyces cerevisiae supplementation on performance, nutrient digestibility and blood metabolites of Awassi lambs. Anim. Feed Sci. Technolo., 231: 131-137.

17. Hansen, H.H., El-Bordeny, N.E. and Ebeid, H.M. (2017) Response of primiparous and multiparous buffaloes to yeast culture supplementation during early and mid-lactation. Anim. Nutr., 3: 411-418.

18. Jouany, J.P. and Morgavi, D.P. (2007) Use of 'natural' products as alternatives to antibiotic feed additives in ruminant production. Anim., 1: 1443-1466.

19. Ghasemi E, Khorvash, M. and Nikkhah, A. (2012) Effect of forage sources and Saccharomyces cerevisiae (Sc47) on ruminal fermentation parameters. African J Anim Sci., 42: $1575-1589$.

20. Jung, H.G. and Allen, M.S. (1995) Characteristics of plant cell walls affecting intake and digestibility of forages by ruminants. J. Anim. Sci., 73: 2774-2790.

21. Hasunuma, T., Uyeno, Y., Akiyama, K., Hashimura, S., Yamamoto, H., Yokokawa, H., Yamaguchi, T., Itoh, M., Mizuguchi, H., Sato, S., Hirako, M. and Kishibiki, S. (2016) Consecutive reticular $\mathrm{pH}$ monitoring in dairy cows fed diets supplemented with active dry yeast during the transition and mid-lactation periods. Anim. Feed Sci. Technolo., 221: 215-225.

22. Whitley, N.C., Cazac, D., Rude, B.J., Jackson-O'Brien, D. and Parveen, S. (2009) Use of commercial probiotics supplement in meat goat. J. Anim. Sci., 87: 723-728.

23. Bueno, M.S., Watanabe, M.H.T., Issakowicz, J. and Sampaio, A.C.K. (2013) Active yeast (Saccharomyces cerevisiae) supplementation improves digestibility of lamb diet. J. Agric. Vet. Sci., 2: 21-26.
24. Guedes C.M., Gonçalves, D., Rodrigues, M.A.M. and Diasda-Silva, A. (2008) Effects of a Saccharomyces cerevisiae yeast on ruminal fermentation and fiber degradation of maize silages in cows. Anim. Feed Sci. Technol., 145: 27-40.

25. Dawson, K.A. and Tricarico, J. (2002) The evolution of yeast cultures-20 years of research. In: Navigating from Niche Markets to Mainstream. Proceedings of Alltech's European. Middle Eastern and African Lecture Tour. p26-43.

26. Deneve, S.A., Peeva, T.Z., Radulova, P., Stancheva, N., Staykova, G., Beev, G., Todorova, P. and Tchobanova, S. (2007) Yeast cultures in ruminant nutrition. Bulg. J. Agric. Sci., 13: 357-374.

27. Wiedmeier, R.D., Arambel, M.J. and Walters, J.L. (1987) Effects of yeast culture and Aspergillus oryzae fermentation extract on ruminal characteristics and nutrient digestion. $J$. Dairy Sci., 70: 2063.

28. Wohlt, J.E., Corcione, T.T. Zajac, P.K. (1998) Effect of yeast on feed intake and performance of cows fed diets based on corn silage during early lactation. J. Dairy Sci., 81: $1345-1352$.

29. Gad, S.M., Tawila, M.A., Abou Ward, G.A., Salama, R. and El-Naggar, S. (2012) Determine the proper level of yeast with different levels of roughages to improve the nutritive value of lamb's ration. Life Sci. J., 9: 1773-1780.

30. Cole, N.A., Purdy, C.W. and Hutcheson, D.P. (1992) Influence of yeast culture on feeder calves and lambs. $J$. Anim. Sci., 70: 1682-1689.

31. Holzer, Z., Levy, D. and Samule, V. (1986) Interactions between supplementary nitrogen source and ration performance and nitrogen utilization in growing and fattening male cattle. J. Anim. Prod., 42:19.

32. Khormizi, S.R.H., Banadaky, M.D., Rezayadi, K. and Zali, A. (2010) Effects of live yeast Aspergillus niger meal extracted supplementation on milk yield, feed efficiency and nutrients digestibility in Holstein lactating cows. $J$. Anim. Vet. Adv., 9: 1934-1939.

33. Raghab E.E., Mehrez, A.F. and Abde-Khalek, A.E. (2003) Digestibility coefficients, blood parameters, feed efficiency and growth performance of weaned Friesian calves fed diet supplemented with Lacto-Sacc. Egyptian J. Nutr. Feeds., 6: 693-702. 